\title{
Article
}

\section{Graphical and Analytical Quantitative Comparison in the Domes Assessment: The Case of San Francesco di Paola}

\author{
Concetta Cusano ${ }^{1, *,+}$, Andrea Montanino ${ }^{2,+} \mathbb{D}^{\mathbb{D}}$, Carlo Olivieri ${ }^{3,+} \mathrm{D}^{\mathrm{D}}$, Vittorio Paris ${ }^{4,+}$ and Claudia Cennamo ${ }^{1,+}$ \\ 1 Department of Architecture and Industrial Design, Universitá degli Studi della Campania "Luigi Vanvitelli", \\ Abbazia di San Lorenzo in Septimum, 81031 Aversa (CE), Italy; claudia.cennamo@unicampania.it \\ 2 Department of Structures for Engineering and Architecture, Università degli Studi di Napoli "Federico II", \\ Via Claudio 21, 80143 Napoli (NA), Italy; andrea.montanino@unina.it \\ 3 Department of Civil Engineering, DICIV, Università degli Studi di Salerno, Via Giovanni Paolo II 132, \\ 84084 Fisciano (SA), Italy; colivieri@unisa.it \\ 4 Department of Engineering and Applied Sciences, Università degli Studi di Bergamo, Via G. Marconi 5, \\ 24044 Dalmine (BG), Italy; vittorio.paris@unibg.it \\ * Correspondence: concetta.cusano@unicampania.it \\ + These authors contributed equally to this work.
}

check for updates

Citation: Cusano, C.; Montanino, A.; Olivieri, C.; Paris, V.; Cennamo, C.

Graphical and Analytical

\section{Quantitative Comparison in the}

Domes Assessment: The Case of San Francesco di Paola. Appl. Sci. 2021, 11, 3622. https://doi.org/10.3390/app 11083622

Academic Editor: Panagiotis G Asteris

Received: 17 March 2021

Accepted: 14 April 2021

Published: 17 April 2021

Publisher's Note: MDPI stays neutral with regard to jurisdictional claims in published maps and institutional affiliations.

Copyright: (c) 2021 by the authors. Licensee MDPI, Basel, Switzerland. This article is an open access article distributed under the terms and conditions of the Creative Commons Attribution (CC BY) license (https:/ / creativecommons.org/licenses/by/ $4.0 /)$.
Abstract: (1) Methods for checking the condition of monumental masonry structures can still be considered understudied. Among the different approaches available in the literature, the graphical ones have a special role, due to their simplicity and effectiveness. (2) In this work, a 2D method (Thrust Line Analysis (TLA)), the Modified Thrust Line Method (MTLM), and the 3D Membrane Equilibrium Analysis (MEA) method are compared. All methods have the same starting concept: no tensile strength, no sliding between the stone blocks, infinite compressive strength. (3) The methods are compared in terms of stress distribution (for the same- or similar—thrust line), and in terms of the Geometrical Safety Factor ensured. (4) The work shows that these theories, if properly conveyed in a scientific methodology (as many authors are doing currently and have done in the past) demonstrate the effectiveness and the advantages of graphical methods for simple structures.

Keywords: masonry domes; thrust line analysis; modified thrust line method; membrane equilibrium analysis; rigid no-tension material; hoop forces

\section{Introduction}

Proper modelling of the mechanical behavior of masonry domes is a crucial task for the correct evaluation of their structural safety, and consequently, to assure their preservation. Masonry structures do not behave as elastic continua, and, due to the intrinsic anisotropic and non-linear response, most of the difficulties in masonry modelling come from its mechanical properties, its heterogeneity (as it is made of blocks usually bonded with mortar) and, of course, from the geometric complexity of the artefact.

Although non-linear analysis remains an essential field of structural investigation in the current scientific context, many studies are looking at on limit analysis as a reliable tool to evaluate the safety factors of masonry constructions.

The current article provides a further deepening of some methods used to examine the state of unreinforced masonry structures, based on the equilibrium approach to limit analysis under Heyman's assumptions of rigid no-tension materials [1].

The theoretical investigation leans on the case study of San Francesco di Paola in Naples, a large dome in masonry conceived of as an assemblage of rigid blocks and subject to the selfweight action. In previous works, this dome has been investigated, with a particular focus on graphical analysis of the dome [2,3], combined with kinematic analysis [4], to define a range of possible displacements, assessing the relative stability of the structure. The dome safety assessment has been evaluated under horizontal actions in some of these works, by performing a thrust membrane analysis through a tilting test [5-7]. 
These works represent the background and the starting point of the present study. As is well known, the fundamental aspect of the graphic statics in the modelling of masonry domes is the analysis of a three-dimensional structural behavior in a bi-dimensional space. Despite being a powerful tool to explain and examine the stability of two-dimensional structures, Thrust Line Analysis (TLA) does not consider the hoop forces, thus producing overly conservative results when applied to three-dimensional cases [8]. On this basis, the present paper aims to explore the role of variable internal meridional and hoop forces by introducing the Modified Thrust Line Method (MTLM) [9] to investigate the equilibrium of the dome. The results obtained are compared with the Membrane Equilibrium Analysis [10], an analytical and general method that can be applied to three-dimensional cases, disregarding the axis-symmetry of the geometry and of the loads. The methods are not further developed with respect to the current literature. The main contribution of this research is to investigate the differences and the points of agreement of the different methods, highlighting the strengths and weaknesses of each of them, also with reference to the presented case study.

Out of the authors' knowledge, there are few works comparing different methodologies applied to masonry structures. TLA and MEA have been used in [5] to assess the seismic vulnerability of San Francesco di Paola; in [11], some differences between TLA and MEA have been highlighted, and both methods are discussed together with the Finite Element Method, following the idea proposed in [12].

\section{Mechanical Behavior of Masonry Domes}

Domes may essentially be defined as vaults with an intrados surface generated by the revolution around its vertical axis. Due to their shape, domes have several advantages: they are generally compressed in all directions and, therefore, suitable to be built in masonry or low-reinforced concrete. They are also subject to very few torsional or bending effects, even at the edges, and present high shape stability [13]. Generally, these structures work in pure biaxial compression, along the meridians and parallels. Like an arch, a dome transfers gravity loads to the base by developing internal meridional forces, which behave as arch actions, always compressive and growing from the crown to the imposts for any uniform and axis-symmetrical load. Unlike an arch, a dome can also develop internal forces along the circumferential direction, known as hoop forces. Meridional and hoop forces, acting perpendicular to each other, allow the dome to be stable, though incomplete, with an oculus. On the contrary, an arch is unstable without its keystone; see Figure 1a,b [14].

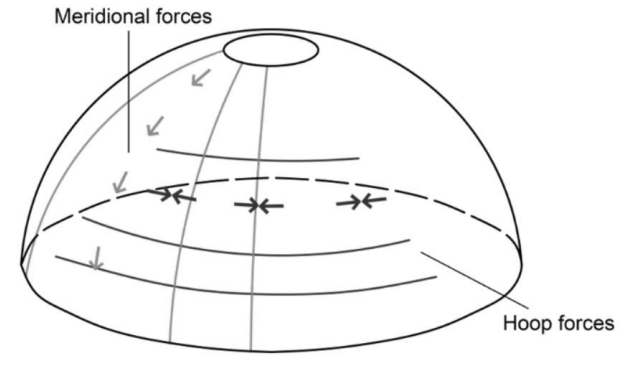

(a)

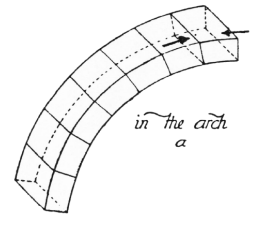

(b)

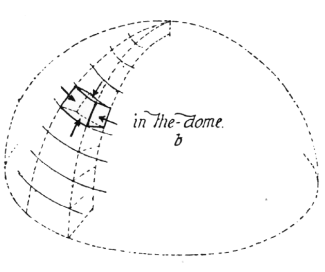

Figure 1. (a) Internal meridional forces and hoop forces in a dome [15]; (b) Comparison between arches and domes. In the arch, you only consider the stresses on the two beds of the arch stones; in the dome, the stones are subject to stresses on all four faces. If the keystone of an arch is removed, the arch must collapse; if the stone in a dome, corresponding to the keystone, is removed, the dome need not fall. The reason is that the horizontal thrust, necessary for the equilibrium, can only be supplied by the keystone in the case of the arch; in the dome, it can be supplied by each ring of stones [16].

The application of the Theory of Membranes to hemispherical geometries returns a biaxial compressive state of stress from the apex of the dome until a latitude of $51.82^{\circ}$ [17]. 
In the remainder, the hoop stress exhibits a tensile behaviour that appears to be in contrast with the theory of Rigid-No-Tension materials. If the whole geometry of the dome is able to contain a different surface for which the corresponding equilibrated stress is of pure compression, the dome will be able to work in compression without the development of cracks. On the contrary, in correspondence of the tensile band, some cracks will develop, as shown in Figure 2, giving rise to a monoaxial compressive stress state along the meridional direction. This stress configuration the basis of the use of the Thrust Line Analysis method for the study of masonry domes.

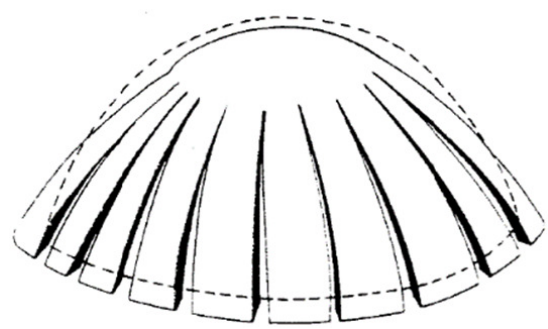

Figure 2. Crack pattern on hemispherical domes [1].

In particular, the meridian stresses vary depending on whether the dome is a single surface, if it has an opening in the center of the top, or it is surmounted by a lantern, as shown in Figure 3.

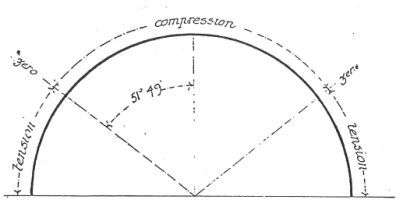

(a)

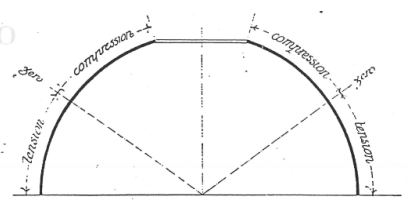

(b)

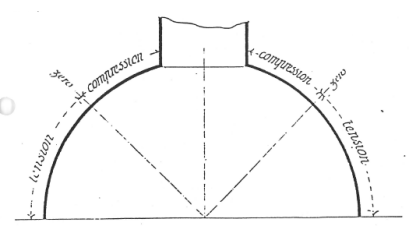

(c)

Figure 3. Stresses on the meridians for the hemispherical dome. (a) In the case of a single surface of revolution, the stresses on the meridian planes are tensions and compressions with zero stress at $51^{\circ} 49^{\prime}$ from the vertical. (b) In the dome with an oculus, the stresses on the meridian planes are similarly tensions and compressions with a point of zero stress with a greater angle than $51^{\circ} 49^{\prime}$, which varies with the opening amount. (c) In the dome surmounted by a lantern, the extent of the tensile stress is increased, and the point of zero stress rises [16].

\section{Evolution of Classical Methods for Assessing the Stability of Vaults and Dome}

The most critical studies on domes have begun from the 18th Century onward, even though the construction of masonry domes dates back to the 17th century. Hooke's centuries-old law of inversion for which "as hangs a flexible cable, so inverted, stand the touching pieces of an arch" remains a milestone of structural theory. Hooke had an intuition that led him to state that an arch in compression has the same, reversed shape of a hanging chain under its own weight [18].

It is possible to analyze complicated vaults and domes with reference to the theory of masonry arches. Though complex, a dome can always be considered as a set of arches and obtained by slicing the dome with meridional planes, forming several arches in the meridional direction [19]. The thrust transmitted by the two ideal half-arches connecting at the keystone must be counteracted at the base to make the arch-system stable. The slicing technique, which analyses two-dimensional sections to assess three-dimensional structures, dates back to Poleni (1748). In his structural analysis of the cracked basilica dome of St. Peter, in Rome [20], Poleni considered the cupola as a series of lunes with internal forces in only meridional directions, namely as wedge-shaped arches not requiring hoop forces to be stable. Inspired by Hooke's law, the method proposed by Poleni can be considered a first statement of the static theorem of limit analysis of masonry structures [20]. Many architects have followed Poleni's principle, among which, Gaudí, at the beginning 
of the 20th century, applied the same principle of the catenary in 3D hanging models to design the Church of Colonia Güell (near Barcelona) and additional complex structures.

A different approach to the analyses of domes was introduced by Schwedler in 1866 [17], who developed the basic equilibrium concept of the membrane theory, which was subsequently refined by Rankine (1904) in [21].

In 1878, Eddy published a graphical method to analyze masonry domes by determining the hoop forces, in terms of both tension and compression, for the membrane stress condition of the vault [9]. While recognizing that hoop forces can mutate within the surface, Eddy considered the dome to be a radial series of arches and, to maintain compression everywhere in the section, he forced the solutions to stay within the middle-third of the section. In the 1920s, Wolfe published a graphical procedure for masonry domes [22] that can be seen as a graphics-based version of the membrane theory introduced by Schwedler. Like the membrane theory, this method fixed internal hoop forces to the values needed to equilibrate the meridional forces. Eddy's approach led to the subsequent development of the Modified Thrust Line Method (MTLM) [23].

During the 19th century, the thrust line analysis and graphic statics marked a further development in the theory of structures by providing a practical method based on the catenary principle. Out of all the modern theories to support classical approaches developed in the first half of the 20th Century, Heyman's Limit Analysis [1] appears to be the most appropriate approach to understand and analyze masonry structures. Heyman's lowerbound theorem (safe theorem) gives the accepted application of plastic theory for the use of lines of thrust for stability assessment. Thrust lines were implemented to assess the stability of arches and vaults in a variety of ways. For details on thrust line construction, the reader can refer to Ochsendorf [24] and Block [25], and refer to Huerta [26] for a comprehensive historical review.

\section{Problem Statement}

\subsection{A Few Initial Remarks}

In this work, we consider three different methodologies (the Thrust Line Analysis, the Modified Line Thrust Method, and the Membrane Equilibrium Analysis) in the framework of limit analysis and apply them to the case study of the dome of San Francesco di Paola, in Naples.

The Thrust Line Analysis (TLA) is based on the slicing technique to reduce the initial three-dimensional problem of the vault in a two-dimensional analysis. Looking at a dome, it consists of dividing it into lunes defined by vertical cutting planes passing through the revolution-axis. In this approach, compressive hoop forces are totally neglected. This initial assumption is not arbitrary, but based on a peculiar physical behavior that can often be seen in masonry domes: the supports spread outwardly a little, and the dome shows typical meridional cracks that are often necessary to accommodate physiological settlements of the supports. In this light, the slicing technique can correctly reproduce this physical behavior by not running into over-conservative solutions. This phenomenon is due to the low tensile resistance of the material. As a result, part of the dome is cut into wedges, and its lower part is subjected to uniaxial compressive stresses in the direction of the meridional cracks.

This aspect does not compromise the structural behavior of domes. The difference between use of the slicing technique and biaxial methods as the membrane theory lies mainly in the upper part of the dome, subjected to a biaxial stress state. Nonetheless, the value of the compressive hoop force is low and does not lead to high differences in terms of results. Although TLA allows for the direct evaluation of such effects, representing a widely accepted assessment strategy, in some cases, it could lead to over-conservative solutions [8].

However, Membrane Equilibrium Analysis (MEA) is a more general method, which naturally considers the presence of biaxial stress regimes; the main drawback is that it requires a more sophisticated mathematical background, losing the characteristic simplicity of other graphical methods. The advantage is that it can be applied to a large variety 
of vaults, disregarding the symmetries of geometries and loads, such as cloister vaults, cross vaults, and others. Some comparative studies between TLA and MEA were recently developed in [11].

The Modified Thrust Line Method (MTLM) conjugates the simplicity of TLA with the possibility of accounting for the presence of hoop forces. The advantage of MTLM is its simplicity, which allows the method to be included in the set of graphical techniques. Hence, the analyses executed through this method can be compared with the TLA analyses to show the influence of hoop forces and those obtained with the membrane solutions.

The aim of this work is to highlight the analogies and differences between the three methods. Based on the case study of San Francesco di Paola, we highlight the differences, strengths and weaknesses of each method, outlining how the parameters used in each method may affect the results. The idea is to provide some hints about simple methods for the study of masonry domes. A simple but complete knowledge of the behavior of masonry domes, possibly with simple instruments, can help to assess the safety of existing masonry buildings, avoiding inappropriate interventions on historic buildings.

\subsection{Previous Applications of the Methods}

Of the three methods under discussion, the Thrust Line Analysis is the more ancient, and was introduced in the form of a graphical method many centuries ago, for the study of the stability of bi-dimensional structures, such as arches, portals, and buttresses. Its extension to axis-symmetric geometries, under the conservative assumptions of a monoaxial-radial-stress regime, was adopted by Poleni for the assessment of the dome of St. Peter Basilica in the Vatican City, in [19]; in $[27,28]$ the method is deeply reviewed, while a historical excursus on its application has been reported in [29].

While a more sophisticated method for three-dimensional geometries has been developed, TLA has remained a first, straightforward starting point for the assessment of domes, and as such, it has been adopted to assess the domes of San Francesco di Paola [2,7] under statics and dynamic loads. It has recently been applied in [11] to study of the doubleshell dome of Santa Maria alla Sanitá and the single-shell dome of San Gregorio Armeno, in Naples.

TLA, however, is still frequently adopted to assess the stability of two-dimensional structures, such as arches, and buttresses. In this field, we recall the works on the Gothic cathedral of Girona [30,31], or on the castle of Bellvar, in Palma de Mallorca [32].

On the contrary, the Modified Thrulst Line Method and Membrane Equilibrium Analysis have been developed only recently. In particular, MTLM was conceptualized to refine the study of masonry domes [23]. Known applications of this method on real structures include the work by Cipriani [33] on some masonry domes in the urban context of Cairo, built in the first centuries of the second millennium, and, more recently, the study of the dome of the church of Santa Maria in Ciel d'Oro in Montefiascone (Italy) [14].

Finally, Membrane Equilibrium Analysis has been proposed for the analysis of masonry vaults with a general shape, not restricted to axis-symmetric cases. Among others, the method has been applied to the cloister vault surmounting a room in Palazzo Caracciolo di Avellino, in Naples, under different load conditions [34], to the cross vaults of the Cathedral of Caserta Vecchia (Italy) [35], and the Gustavino helical stairs [36].

\subsection{Materials and Methods}

This section describes the procedures adopted to evaluate the stability of the dome, together with the parameters assumed in the study.

According to Heyman's assumptions-for which masonry (i) has no resistance in tension; (ii) has an infinite compressive strength; (iii) cannot undergo sliding mechanismsthe dome is modelled as composed of rigid-unilateral material that is resistant to compressive loads but not to tensile loads. The masonry material is then conceived as a set of non-deformable blocks supporting their own weight, in dry and direct contact; the stresses are so low, and friction is so high between voussoirs, that stones are effectively interlocked, 
thus preventing any sliding mechanism. Furthermore, as stated in the Safe Theorem, lines of thrust may efficiently represent the stability of domes, which depends on the geometrical distribution of loads, rather than the mechanical properties of masonry material, which may not be rigorously established.

In the following, we recall the fundamentals of the three methods adopted in this paper for the assessment of the case study, also discussing the potentiality of each of this method for the evaluation of the Geometrical Safety Factor (GSF), the traditional parameter adopted to quantify the level of safety of a masonry structure. GSF is defined as the ratio between the thickness of a vault and the maximum thickness reduction for which it is possible to draw at least one thrust line (or surface), under the same loads.

Given the maximum percentage reduction $d$, the geometrical safety factor is computed as

$$
G S F=\frac{1}{1-d}
$$

\subsubsection{Thrust Line Analysis}

The Thrust Line Analysis (TLA) was first developed for two-dimensional structures, like arches and buttresses, and successively applied to axis-symmetric structures. Its suitability, however, is extended to all cases for which a mono-axial stress regime can be assumed for the equilibrium of a structure.

The method consists of dividing a structure into a finite number of elements (voussoirs), each one with its weight, and drawing the loads path between blocks, mainly recurring to graphic methods.

According to the Safe Theorem of Limit Analysis, the equilibrium and stability of the structure are assessed if at least one line of transmission of loads passes within the intrados and the extrados of the structure.

It is well known that for stable structures, there is an infinite number of lines of thrust that can be computed. However, they depend on only two parameters: the initial point of the thrust line and the value of the horizontal thrust. It is then very easy, through an automatic procedure, to draw all the possible thrust lines of a structure.

\subsubsection{Modified Thrust Line Method}

The MTLM is a graphic static tool developed by Lau in 2006 [23]. Similarly to TLA, it allows for assessment of the state of axisymmetric masonry structures through the use of the thrust line. Indeed, according to the Safe Theorem, a balanced state is guaranteed if at least one thrust line lies entirely within the thickness of the analyzed structure.

Differently from TLA, the lines of thrust obtained through MTLM also consider the contribution of the hoop forces. This implies that, in addition to the Heyman premises, this method requires further assumptions for the assessment of the equilibrium of the dome [37] —namely, the load has to be axisymmetric, as well as the geometry of the structure. Under these additional constraints, the state of a dome is determined by studying the equilibrium of only one lune, representative of the whole dome. As shown in Figure 4, the lunes are obtained by dividing the structure into equal parts with vertical radial planes.

Similarly to TLA, the lune is divided into blocks referred to with a index $i$, running from the impost to the top of the vault, with mass $m_{i}$ and centroid $C_{i}$. For each block, one point $A_{i}$ is determined as the intersection of the vertical line passing through $C_{i}$ and the resultant of all the loads of the blocks from 1 to the current block $i$. Therefore the thrust line is obtained as the set of all points $A_{i}$. The determination of each point $A_{i}$ follows the same logic as that adopted for TLA; it is affected by all forces and requires a solution to the equations of equilibrium of each block.

$$
\mathbf{P}_{i}-\mathbf{R}_{i}+\mathbf{w}_{i}+\mathbf{H}_{r i}-\mathbf{H}_{l i}=0
$$

For each block, $i$. Considering a generic $i$-th block, Equation (2) expresses the equilibrium at the point $\mathbf{A}_{i}$, and involves the thrust $\mathbf{P}_{i}$ of the upper blocks, the reaction $-\mathbf{R}_{i}$ from 
the lower blocks, the weight of the block itself $\mathbf{w}_{i}$ and the two forces $\mathbf{H}_{r i}$ and $\mathbf{H}_{l i}$ which represent the action of the hoop forces acting on the block. Due to static indetermination, Equation (2) cannot be solved: the thrust, reaction and the hoop forces are all unknown.

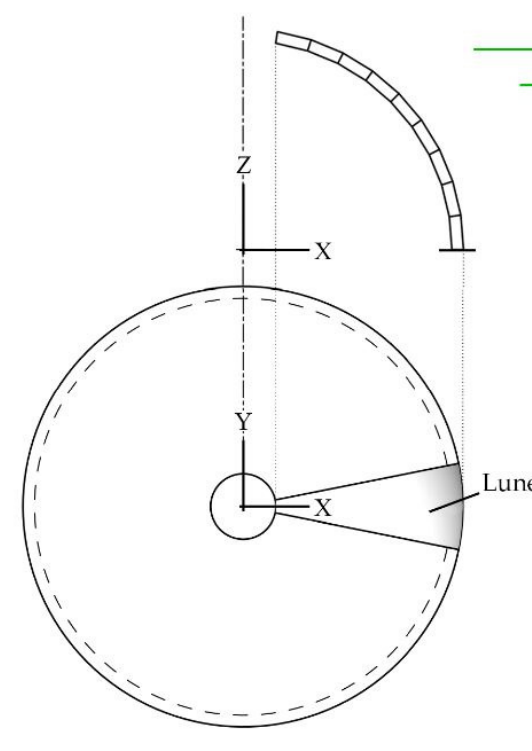

(a)

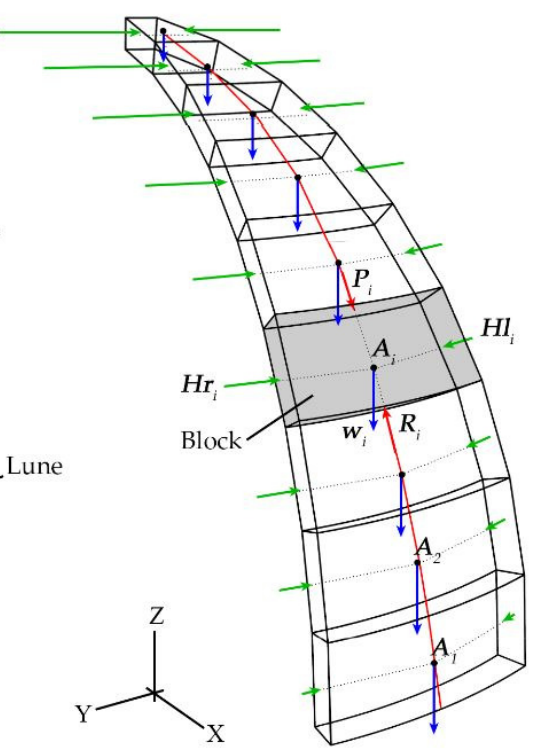

(b)

Figure 4. (a) Bottom, plan view of hemispherical dome and a lune. Top, elevation view of a lune divided into blocks. (b) three-dimensional view of a lune and the forces acting on it. The hoop forces are highlighted in green; in blue, the masses of blocks, and in red, the thrusts.

For each block $i$, the terms of Equation (2) are $-\mathbf{R}_{i}, \mathbf{H}_{r i},-\mathbf{H}_{l i}$ and $\mathbf{w}_{i}$; thanks to the symmetry of load and structure, the two hoop forces are equal and the unknown variables are two (the radial thrust and the hoop forces). Furthermore, for all blocks, the reaction which acts on the upper rigid body is the reverse of thrust applied on the lower block. Therefore, by estimating the hoop forces and starting from the uppermost block, the position of all points $A_{i}$ is identified, and the thrust line is traced.

To solve Equation (2), the hoop forces are estimated by an optimization algorithm [23] or by graphical manipulation [14]. In the present work, the MTLM has been implemented into the graphical editor algorithm Grasshopper [38] for Rhinoceros software [39], and the hoop forces are estimated by graphical manipulation [14]. According to the further assumptions (load and geometry are axisymmetric) and considering the compressive forces to be positive, the hoop forces are sought based on the guiding criterion that they act normally to the lateral block face, and their magnitude decreases from the crown to the base of the dome.

With MTLM, it is possible to compute the geometrical safety factor with the same general definition given in Equation (1). The difference with respect to TLA is that, with MTLM, the thrust surface depends not only on two parameters, but also on the value of the hoop forces at each voussoir. Therefore, it is practically impossible to check all the possible equilibrium curves, and the search for the GSF of a structure must be done using well-established optimization tools.

The higher number of degrees of freedom in the MTLM, however, ensures that it is always possible to find a thrust line closer to the middle surface of the structure, permitting a higher thickness reduction, and finally, a higher geometrical safety factor.

\subsubsection{Membrane Equilibrium Analysis}

The Membrane Equilibrium Analysis (MEA) is a complete analytical tool to assess the stability of a vault and find a possible state of stress, under the restrictions of Rigid 
No-Tension (RNT) materials. The driving criterion is again the Safe Theorem of Limit analysis, particularized to three-dimensional structures.

Differently from the previously considered methods, MEA is a more general numerical tool, which does not need any preliminar consideration of the symmetry of the geometry and of the loads, and is, therefore, also adopted in complicated vaults, such as cloister vaults or cross vaults.

In MEA, the equilibrium of a vault is assessed through the search for a membrane surface, comprised inbetween the intrados and the extrados of a vault, capable to equilibriate the assigned load with a purely compressive membrane stress field [34,40,41].

The theoretical framework adopted here has been proposed in previous works [10,40,42], and consists of solving the equilibrium equation

$$
\operatorname{div} \mathbf{T}+\mathbf{b}=\mathbf{0}
$$

for membranes, where $\mathbf{T}$ is the membrane generalized stress-that is, the stress for unit thickness of the membrane-and, therefore, is measured as a force per unit length, and $\mathbf{b}$ is the applied load. The membrane behavior allows for the assumption that the stress can be expressed in a membrane reference system as

$$
\mathbf{T}=T^{\alpha \beta} \mathbf{a}_{\alpha} \otimes \mathbf{a}_{\alpha}
$$

where the assumption of summation over repeated indices is implicit; moreover, $\mathbf{a}_{\alpha}$ is a curvilinear covariant basis vector, tangent to the membrane geometry, and $T^{\alpha \beta}$ is a contravariant component of the generalized stress. After some algebra, which is out of the scopes of this work, but is reported in $[41,43]$, we reach the transversal equilibrium equation of the membrane

$$
F_{, 22} f_{, 11}+F_{, 11} f_{, 22}-2 F_{, 12} f_{, 12}+p=0
$$

where $f=f\left(x_{1}, x_{2}\right)$ is the geometrical description of the membrane, $x_{1}$ and $x_{2}$ are the Cartesian coordinates of a horizontal plane; $F$ is a stress potential, defined such that $F, 11=S^{22}$, $F_{, 22}=S^{11}$, and $F_{, 12}=-S^{12}, S^{\alpha \beta}$ being the components of the Pucher stresses-that is, the projection of the generalized stress $\mathbf{T}$ onto the planform of the membrane-and, as such, are measured again as a force per unit length, that is, in $\mathrm{kN} / \mathrm{m}$. In particular, $S^{\alpha \beta}=J T^{\alpha \beta}$, where $J$ is the ratio between an infinitesimal area onto the membrane and its projection onto the horizontal plane; moreover, a subscript after a comma denotes partial derivative; finally, $p$ is the distributed vertical load.

Equation (5) is a second-order partial differential equation, where the stress potential and the shape are both unknown. It can, however, be solved if at least one of the two functions are assigned. This can be done by assigning a shape (comprised between the geometrical boundary of the vault), and assuming the stress potential as unknown: in this case, the compressive state of the resulting stress has to be checked, and in case, a new membrane shape has to be assigned [41]; in this case, to numerically solve Equation (5), the ellipticity of the Equation that corresponds to the concavity of the assigned surface should be assured.

On the contrary, Equation (5) can be solved for the membrane shape, given an assigned compressive stress state. In this case, the Equation is elliptic by definition, since the assigned stress state is compressive under the Safe Theorem, and, therefore, the stress potential is concave. This method allows for the assessment of non-concave surfaces, as proposed recently by [44].

In this work, we consider only concave shapes for the membrane, and for the application part, we choose one of the possible concave shapes obtained through MTLM. For its numerical solution, we adopt the Lumped Stress Method (LSM) [45], which is a well-established numerical tool for boundary value problems. It consists of approximating the membrane surface $f$ in a finite number $N_{t}$ of linear triangles and $N_{n}$ nodes, 
which correspond to the nodal elevation of the membrane, namely $f_{i}, i=1, \ldots, N_{n}$. From a suitable discretization and solution of Equation (5), according to the LSM, it is possible to obtain the corresponding nodal values of the stress potential $F_{i}$, that, using the same triangulation, give rise to a folded three-dimensional solid representing a discretized stress potential. From the nodal values of the stress potential, it is possible to retrieve the Pucher stresses, and, finally, the generalized stresses. The last check is to verify that the stress is always negative semidefinite, according to the Safe Theorem of Limit Analysis requirements. If so, the problem is solved, and the safety of the structure is checked; otherwise, a new membrane surface has to be adopted, iterating the procedure until a shape-stress potential is found that fulfils the requirements of the Safe Theorem of Limit Analysis for masonry.

For membrane analysis, the computation of the geometrical safety factor of a structure is even more complicated with respect to the other two methods, given the even higher number of degrees of freedom. That is equal to the number of nodes of the discretization of the domain. The dimensionality of the problem can, however, be reduced for axissymmetric domains, such as in the present case study, but a fast optimization tool, that is also able to reject those surfaces for which positive stresses arise, is still needed.

The assumed limitation on concave membrane surfaces reduces the space of applicability of MEA, and, therefore, can have a consequence for the GSF, since some non-concave surfaces, accessed by MTLM, cannot be accessed by the present version of MEA.

\section{The Case Study of San Francesco di Paola}

In the present section, we apply the methods recalled in the previous sections to the case study of San Francesco di Paola, in the historical center of Naples (Italy). We first make a brief excursus ona previous calculation made in the literature for the assessment of this church, then give some details about the geometrical characteristics of the dome, and finally apply the different methods under discussion.

\subsection{Previous Calculation on the Case Study}

The Church of San Francesco di Paola in Naples is a majestic building that surprisingly has barely been studied, probably because of its architectural features, which resamble the type established by the Pantheon in Rome, despite it being a neoclassic building erected in the 19th century. Thus, few documents are available in the literature on its more proper structural and constructive aspects. However, it arouses great interest due to its substantial and massive structure: its dome has an impressive $36 \mathrm{~m}$ span (the fourth largest dome in Italy).

The geometry used for the calculation is done with an analysis by laser-scanner and a photogrammetric survey carried out in collaboration with Tecno IN Geosolutions [2].

Recently [4], the stability assessment of the dome of San Francesco di Paola under vertical loads has been discussed using both the kinematic theorem and the safe theorem of limit analysis; by combining kinematic and static approaches, it was possible to comprehend the range of possible movements of the masonry structure and evaluate its relative safety. The most interesting aspect of this research concerns the idea that traditional masonry structures can be analyzed as rigid blocks whose collapse can occur, for example, due to variations in the applied load, long-term failures or accelerations of the ground. It has also been emphasized that the kinematic of historic masonry dome has an important role in assessing the stability of such structures. In fact, displacements are common in historic masonry structures due, for example, to the consolidation of materials, imperfections in construction or differential settlements in foundations [46-48]. For these traditional masonry buildings, it is more likely that collapse occurs due to excessive subsidence or accelerations of the ground, rather than to an applied load.

The assessment of this dome under horizontal actions has been studied in $[5,7]$. The horizontal force capacity of the dome-buttress system has been evaluated through a tilting test, adopting MEA and TLA as for the related evaluations. The work aimed to determine the limit value of the dome inclination for which the masonry is still entirely 
compressed and to assess the buttress stability. The results show that TLA is more conservative with respect to MEA for this kind of analysis, giving a lower limit rotation angle for TLA with respect to MEA.

\subsection{Geometrical Parameters}

In the following, some descriptive and constructive information about this dome, its geometry and the parameters used to model the structure, are presented before the proper structural analysis.

The analyzed dome, hemispherical in shape, has a diameter of $36 \mathrm{~m}$ and a height of about $22 \mathrm{~m}$ from the base to the key, made entirely of masonry. Note that this different ratio between the diameters confers a greater slimness to the dome, by configuring it as a not perfectly hemispherical shell. Outside, the shape of the dome appears more complex than the internal one: downwards, the cylindrical wall becomes a terraced wall, divided into seven climbs covered by leads. With this wall ring around the foot of the cupola, the builder inhibited side slipping and provided a counter-weight that strengthened the cupola in its lower zone, crucial for its stability, as shown in Figure 5a. At the top, the dome ends with a compression ring that surrounds the opening in the center, with a diameter of $8.20 \mathrm{~m}$. This ring is about $55 \mathrm{~cm}$ thick and about $145 \mathrm{~cm}$ high, and a lantern-made of glass and iron-surmounts it, as can be seen in Figure $5 \mathrm{~b}$. The dome is supported by a tambour resting on eight polygonal pylons, with a base of $9 \mathrm{~m}$ by $4 \mathrm{~m}$, interspersed with twenty columns. Several tribunes have been realized inside the tambour, used by the royals to attend religious services. Regular brick walls comprise the tambour structure, which is empty inside, with a circular path along its entire circumference, as shown in Figure $5 c, d$; externally, Gaeta limestone covers its surface [2,3].

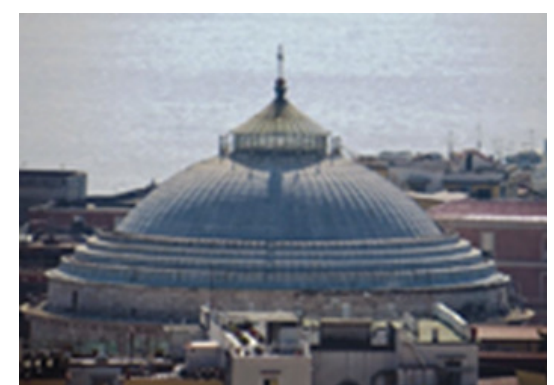

(a)

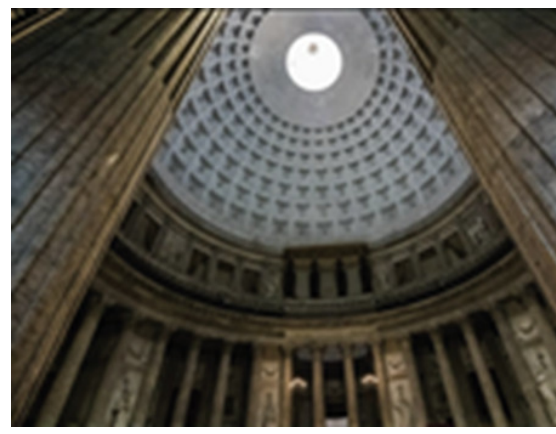

(c)

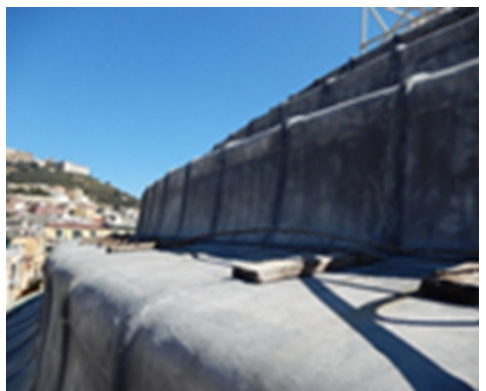

(b)

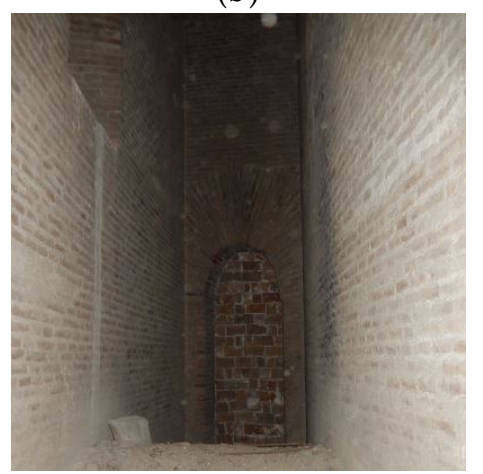

(d)

Figure 5. Dome of San Francesco di Paola in Naples: (a) external view; (b) details of the terraced wall divided into steps; (c) general view of the interior of the church; (d) picture of the path inside the tambour.

Figure 6 shows the transverse section of the structure, used in the analyses, and outputs the geometry obtained from earlier studies [2,3]. The analyses performed in this paper consider only the dome's cap (from the angle of $24.80^{\circ}$ ), since it represents the critical part for equilibrium and stability, considering that in the lower portion, in accordance with the circular steps, the thickness increases. In fact, with this ring of walls around 
the foot of the cupola, the builder inhibited side-slipping and provided a counter-weight that strengthened the cupola in its lower zone, crucial for stability.

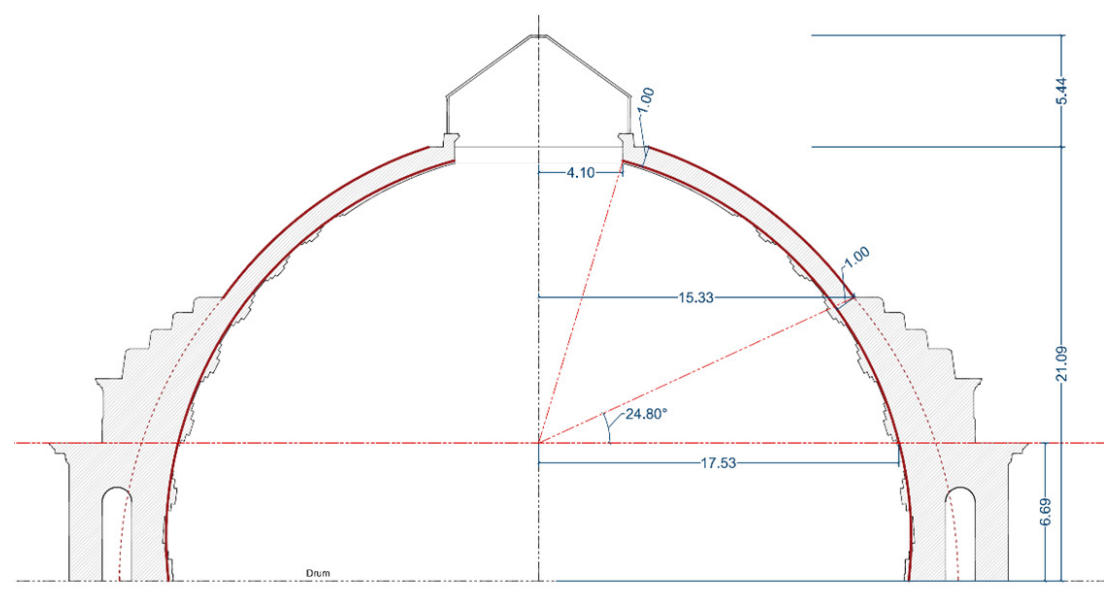

Figure 6. Transverse section and geometry of the dome.

Based on the above considerations, we fixed the properties and parameters for the analyses presented in Section 4. The dome is considered only when subjected to its self-weight, and it divided into 32 spherical sectors, called lunes, as prescribed by Heyman [49]. For the MTLM, each slice, in turn, was divided into 75 voussoirs, equally spaced across its length. In the literature, it is common to consider 7 voussoirs sufficient for a correct evaluation of the thrust lines. This is due to the fact that TLA and its modified versions were performed graphically. With computer software, this number can be increased. In this work, 75 voussoirs were considered a good trade-off between the computational cost and the needed accuracy of the results. We considered a tuff density of $18.00 \mathrm{kN} / \mathrm{m}^{3}$ for the material. The lantern weight is $W_{L}=1600 \mathrm{kN}$.

From a strictly procedural point of view, we first use the MTLM to select a thrust surface between the intrados and the extrados of the membrane. This surface is used as a guess surface for MEA, in order to compare the results; finally, since, with TLA, the same profile cannot be obtained, among the possible thrust sufraces, we select the one that is closer to that obtained with MTLM (see Figure 7).

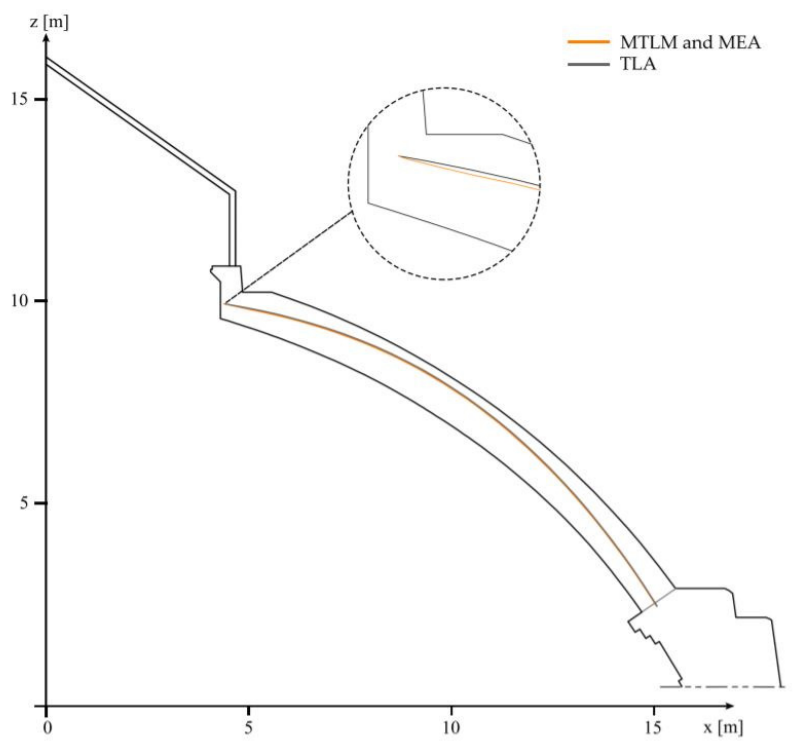

Figure 7. Overlay of the thrust lines. 


\subsection{Application}

\subsubsection{MTLM and TLA}

Using MTLM, we obtain a horizontal thrust in the upper part of the dome $P x_{75}=$ $170.0 \mathrm{kN}$, which increases for the first five voussoirs then stabilizes at a value of $322.5 \mathrm{kN}$ (see Table 1). This is due to the fact that these first five voussoirs absorb the lantern load, showing a significant hoop forces value that, from the sixth voussoirs onwards, is almost zero. The variation in the thrust component $P x_{i}$ is clearly shown in the force polygon in Figure 8.

Table 1. Data comparison between TLA and MTLM in terms of thrusts and hoop forces in the upper part of the dome (voussoir 75) and in the bottom part of the dome (voussoir 1). All values are reported in $\mathrm{kN}$.

\begin{tabular}{ccccccc}
\hline & $\mathbf{P}_{\mathbf{x} 75}$ & $\mathbf{P}_{\mathbf{y} 75}$ & $\mathbf{P}_{\mathbf{x} \mathbf{1}}$ & $\mathbf{P}_{\mathbf{y} 1}$ & $\mathbf{H}_{\mathbf{1 7 5}}$ & $\mathbf{H}_{\mathbf{1 1}}$ \\
\hline MTLM & 170.0 & 54.9 & 322.5 & 628.8 & 867.2 & 0.16 \\
TLA & 323.7 & 54.9 & 323.7 & 628.8 & 0 & 0 \\
\hline
\end{tabular}

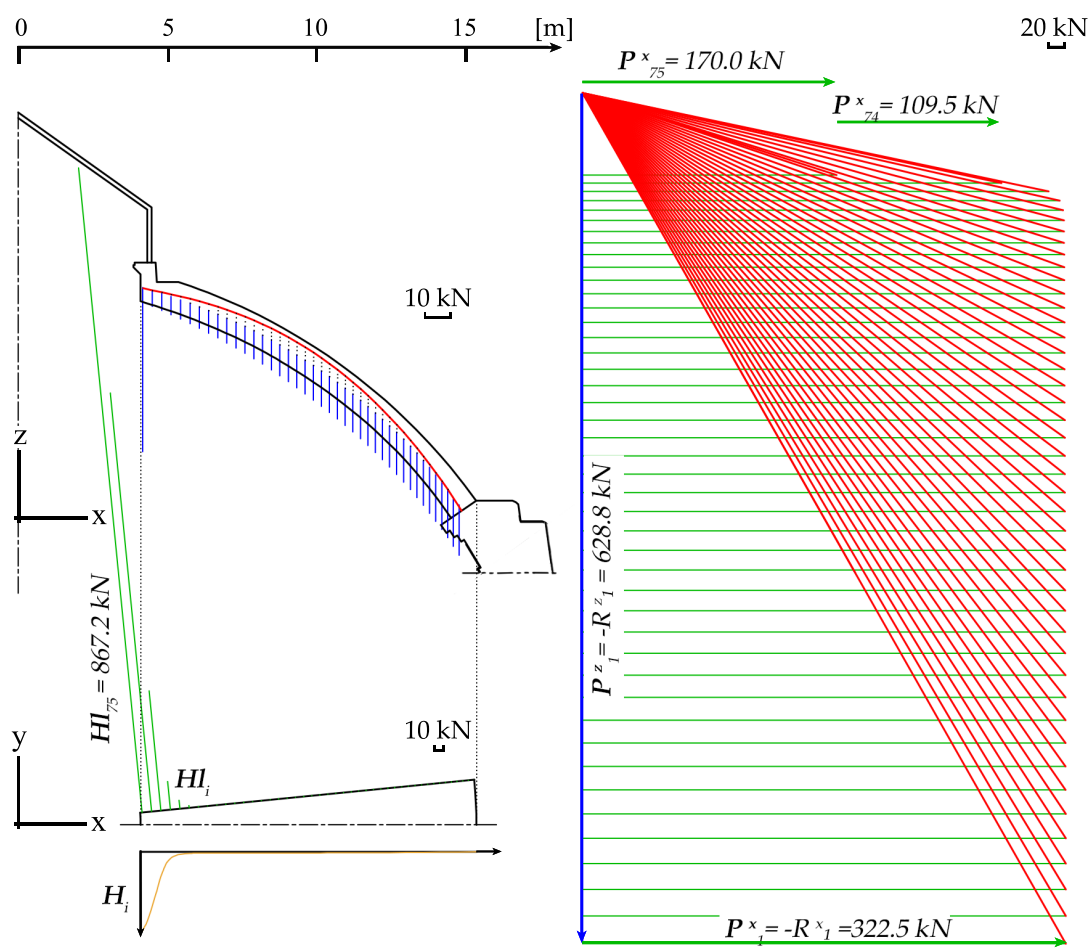

Figure 8. Equilibrium of the dome of San Francesco di Paola with MTLM. In the dome section (top left), the thrust line is drawn in red and the vectors representing the weight of each voussoir are drawn in blue. In the force polygon (on the right), the horizontal thrust is outlined in green and the vertical thrust in blue. Bottom-plan view of the lune with hoop forces (bottom left) plotted in green; the hoop forces' distribution is shown in orange.

The classical method of TLA can be derived as a particular case of the MTLM, by imposing a vanishing behavior of the hoop forces along each meridian. The most evident consequence in terms of thrust is that the thrust itself is constant from the top to the bottom of the dome.

It is worth noting that, with classical TLA and MTLM, it is not possible to obtain the same profile for the thrust line. Among the infinite set of thrust lines that can be obtained using the slicing technique, we choose the one which returns as similar a profile as possible to the one selected with the MTLM by fixing the points of passage of the thrust line in the upper and lower part of the dome and considering a horizontal thrust value $P x_{75}=P x_{1}=323.7 \mathrm{kN}$ (see Figure 9). 


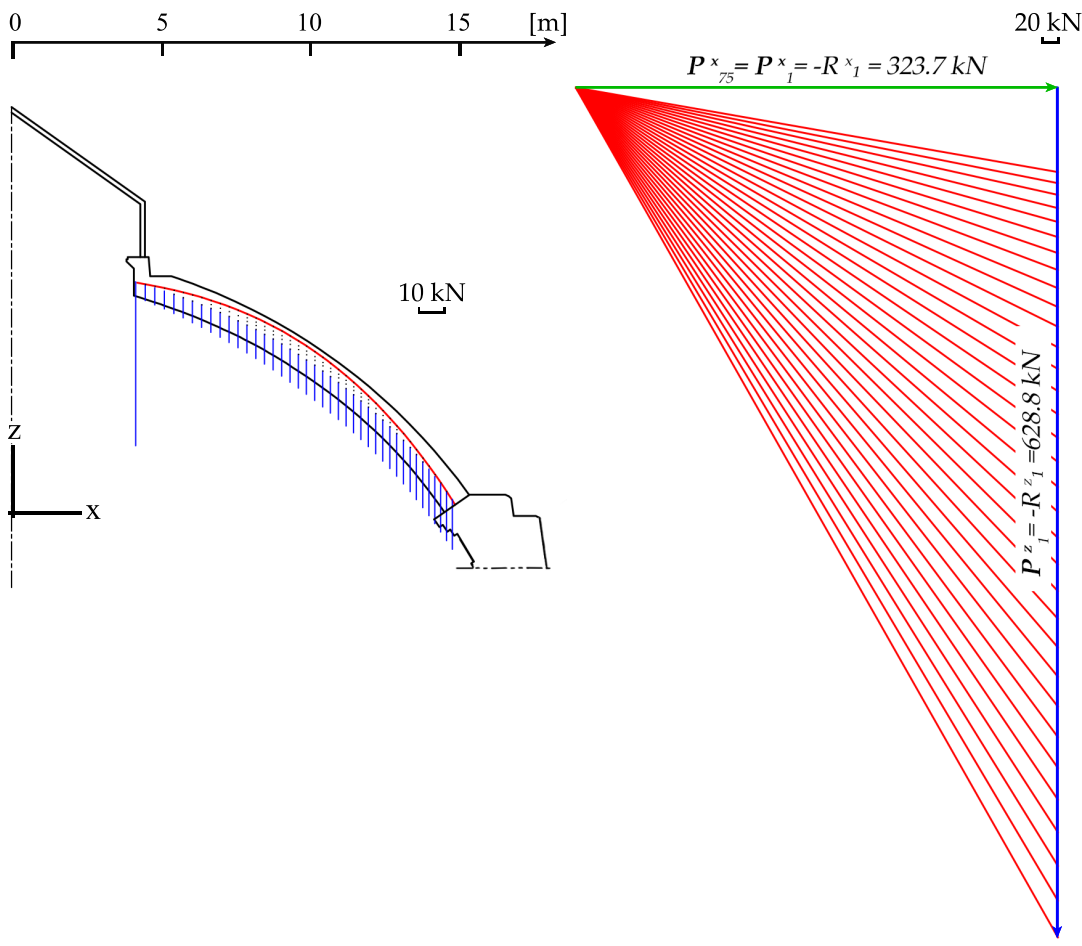

Figure 9. Equilibrium of the dome of San Francesco di Paola with TLA. In the dome section (on the left), the thrust line is drawn in red and the vectors representing the weight of each voussoir in blue. In the force polygon (on the right), the horizontal thrust is outlined in green and the vertical thrust in blue.

The result of the comparison of these two methods is that the vertical component of the thrust is the same, due to the considered loads; additionally, the vertical component of the thrust in the lower part has an almost similar value. However, the horizontal component in the upper part of the dome through the TLA is significantly lower than the one obtained with the MTLM, since there is a strong contribution of the hoop forces in this part that is not considered by the classical TLA (see Table 1).

\subsubsection{MEA}

To apply the methodology introduced in Section 3.3.3 we consider the curve represented in Figure 7 as the starting point to obtain the membrane shape. Figure 10 shows the membrane obtained through the revolution of the thrust line about the vertical axis, and the corresponding stress potential obtained through a numerical solution of Equation (5) by the LSM.

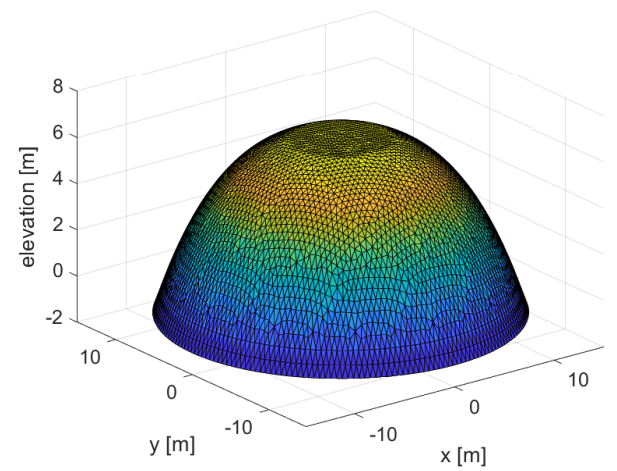

(a)

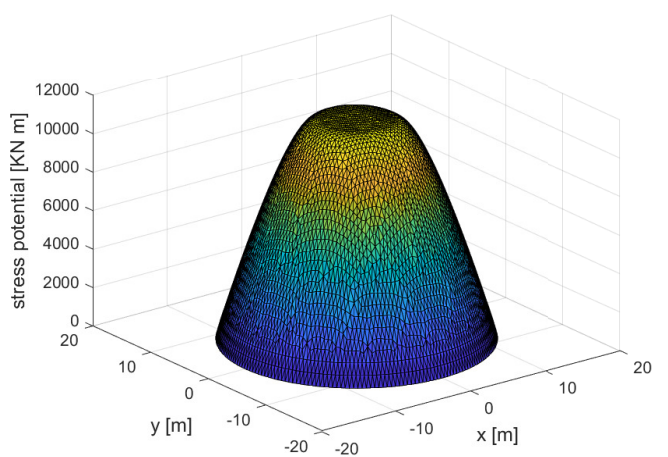

(b)

Figure 10. Membrane Equilibrium Analysis: application to the dome of San Francesco di Paola: (a) membrane shape; (b) stress potential. 
From Figure 10b we notice that the stress potential has the shape of a convex solid; therefore, all the principal stresses are negative semidefinite, according to the definition of the Pucher stresses.

In Figure 11 we show the principal value distribution of the Pucher stresses. We notice that both principal stresses are negative in all the domain, fulfilling the requirements of the Safe Theorem of Limit Analysis; therefore, the membrane chosen for the analysis is one of the possible geometries that carry the loads acting on the dome. In Figure 12 we also show the radial and hoop generalized stresses along a meridian.

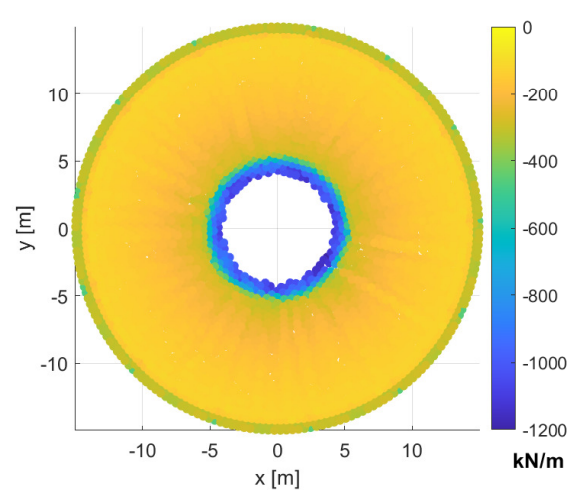

(a)

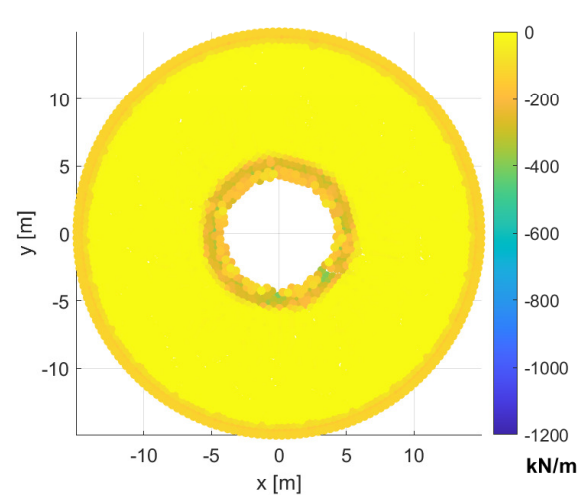

(b)

Figure 11. Membrane Equilibrium Analysis: minimum (a) and maximum (b) principal values of the Pucher stresses.

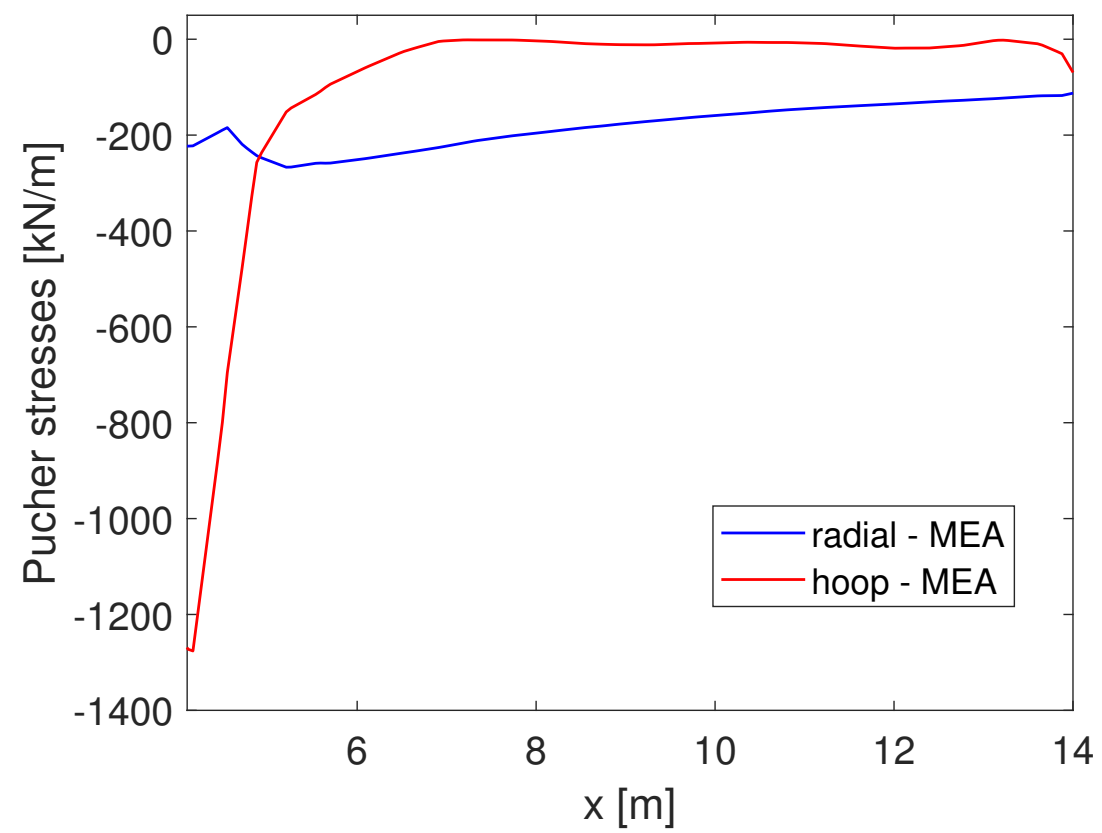

Figure 12. Radial and circumferential Pucher stresses along a meridian using MEA.

\subsection{Geometrical Safety Factors}

In this section, we show the geometrical safety factor computed with the different methods. As mentioned in Section 3, for TLA it is easy to span all the possible curves and find the one that is the closest to the midsurface of the vault.

For the case study of San Francesco di Paola, in Figure 13 we show the most internal possible thrust line and the virtual intrados and extrados that mark the maximum possible thickness reduction in the vault. In this case, the maximum thickness reduction is $d=62.4 \%$, which corresponds to a geometrical safety factor $G S F=2.65$. 


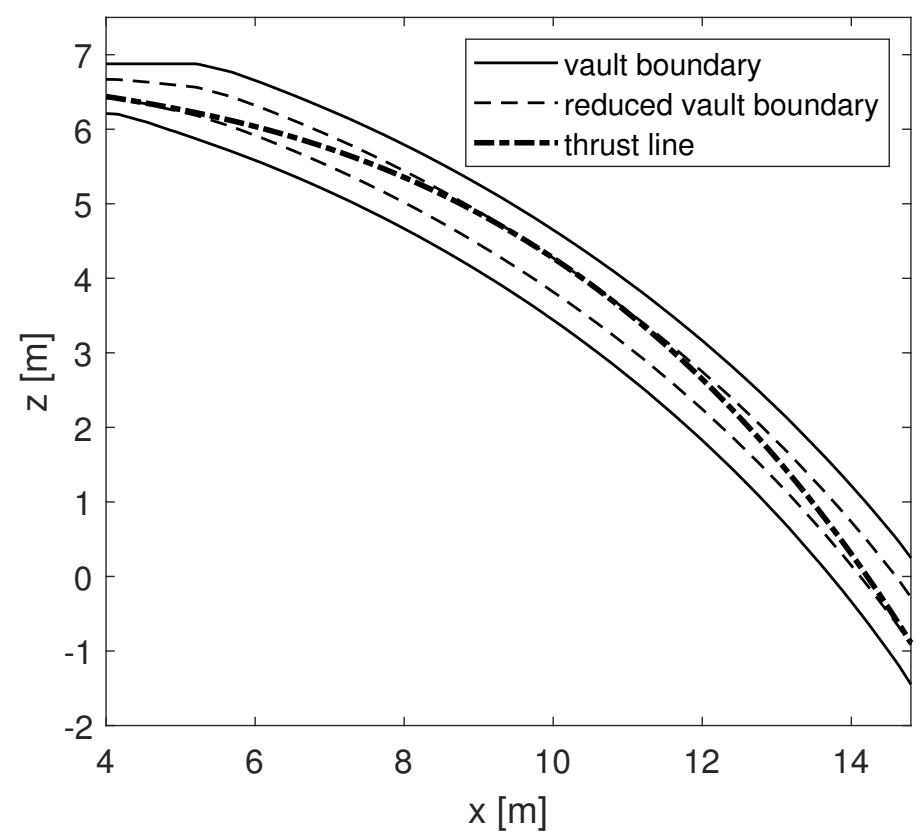

Figure 13. Thrust line obtained using TLA in the safest case.

The computation of the geometrical safety factor with MTLM requires a more complicated optimization algorithm, capable of finding the best combination of hoop forces at each voussoir to minimize the distance of the thrust line from the midsurface.

The higher flexibility of MTLM with respect to TLA allows for a higher geometrical safety factor. Our optimization algorithm is able to reduce the overall thickness of the vault of $d=80 \%$, with a corresponding safety factor GSF $=5.00$, as shown in Figure 14 .

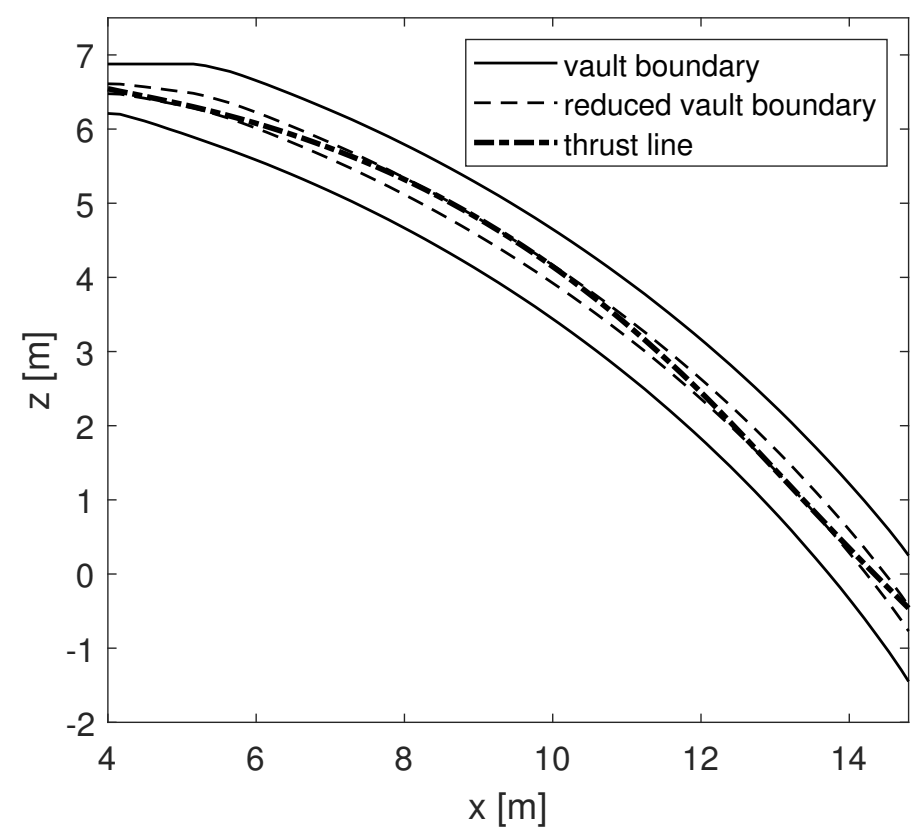

Figure 14. Thrust line obtained using MTLM in the safest case.

Concerning MEA, the algorithm presented in the present paper does not permit access to non-concave membrane surfaces. For non-concave surfaces, the problem could be approached by assigning the stress potential, which is convex with the definition of No-Tension material, and solving it for the shape, as recently shown in [44].

Therefore, we limit our study the evaluation of the geometrical safety factor with MEA to concave shapes. We use a trial-and-error algorithm to explore some of the possible 
membrane surfaces to which the negative semidefinite stress tensor corresponds. Finally, we obtain the shape shown in Figure 15, which fills into a thickness reduced by $67 \%$ with respect to the original, which corresponds to a geometrical safety factor of GSF $=3.03$.

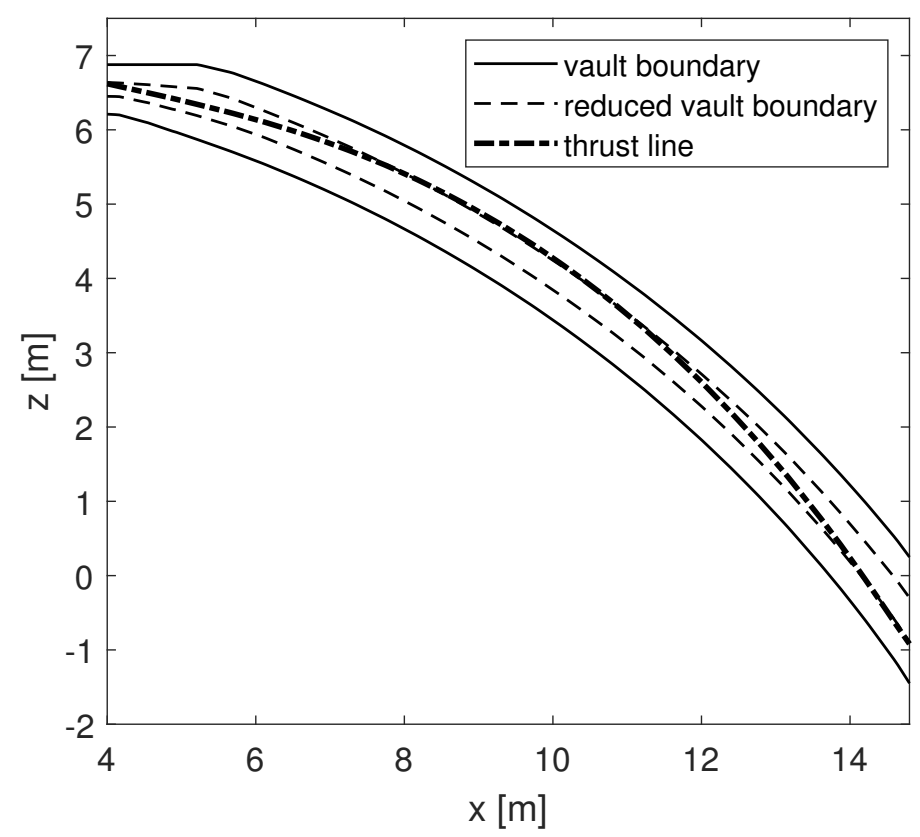

Figure 15. Thrust line obtained using MEA in the safest case.

\section{Results and Discussion}

In this section, we compare the results obtained from TLA, MTLM and MEA. Restricting ourselves to the case of axis-symmetric structures (for which MTLM and TLA can be applied), a first consideration can be made of the similarities of the thrust lines, which cannot coincide. In fact, introducing hoop forces in the formulation modifies the thrust lines obtained with the TLA, even when starting with the same thrust value at the top of the vault.

The similarities and differences in these methods can be evaluated by comparing the thrust at the base of the dome and the radial and circumferential stress distributions, in the case in which a similar thrust line profile is followed, and the optimized GSF in the case in which the objective of the analyses is optimization.

Concerning the thrusts, with particular reference to graphical methods, in Table 1 we notice that, following a similar thrust line profile, for TLA, the horizontal thrust is the same along the meridian, and, of course, the hoop forces are vanishing; on the contrary, after adopting the MTLM, the radial thrust increases along the meridian due to the presence of the hoop forces.

Concerning the stresses, MTLM and MEA can be compared after a suitable conversion of the static entities is made. In MTLM, the computation is made in terms of forces, whereas MEA is formulated in terms of generalized stress, and finally, using the Pucher stresses, which are the projection of the membrane-generalized stress $T$ onto the domain of the membrane geometry.

To compute the circumferential Pucher stress from the MTLM hoop forces, for each block, $i$, we divide the force $H_{i}$ by the lateral area of the block, and then we multiply it by the vertical average thickness of the voussoir itself.

Concerning the radial stresses, we start from the contact force $P_{i}$ along the meridian between two blocks: we consider the component along the $x$-axis and divide this by the contact area, and multiply again by the vertical thickness of the voussoir.

A comparison between the results, in terms of Pucher stresses, is summarized in Table 2 and shown in Figure 16. 


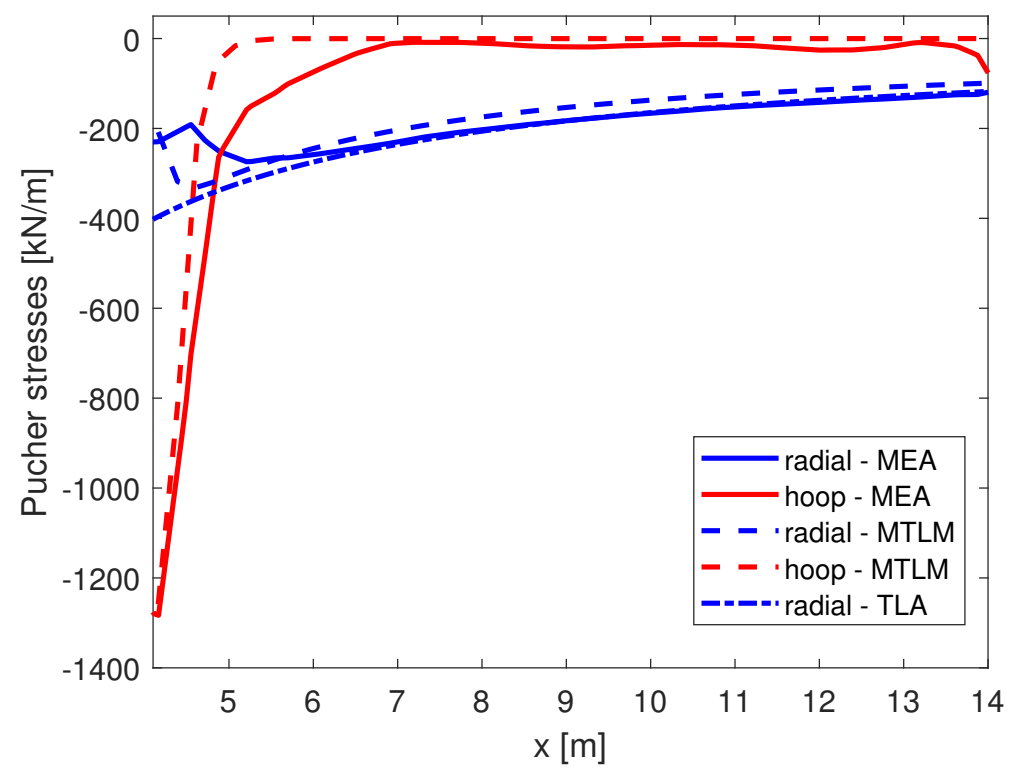

Figure 16. Plot of the projected generalized stresses obtained through MEA, MTLM and TLA.

Table 2. Data comparison between TLA, MTLM, and MEA in terms of projected stresses (Pucher stresses) in the upper part of the dome (voussoir 75) and in the bottom part of the dome (voussoir 1). All values are reported in $\mathrm{kN} / \mathrm{m}$.

\begin{tabular}{ccccc}
\hline & Radial $_{\mathbf{7 5}}$ & Radial $_{\mathbf{1}}$ & Hoop $_{\mathbf{7 5}}$ & Hoop $_{\mathbf{1}}$ \\
\hline MTLM & 208 & 100 & 1258 & 0 \\
TLA & 401 & 118 & 0 & 0 \\
MEA & 201 & 117 & 1280 & 50 \\
\hline
\end{tabular}

From Figure 16 we notice that, for the same (or similar) thrust line, there is a slightly different stress distribution for the three methods, especially in the upper part of the dome (small values of the radius). In fact, when hoop stresses are admitted (MTLM and MEA), in the central part, high hoop stresses arise and the radial stress remains quite low. Some differences remains between the two methods, due to the distribution of the load of the lantern among the first voussoirs from the top (MTLM) and a ring around the lantern for MEA. In fact, MEA cannot handle concentrated loads; therefore, the load of the lantern must be spread over a finite area. TLA does not allow hoop stresses, and therefore, for similar thrust lines with respect to the other two methods, there are different (higher) values for the radial stresses near to the dome crown. At the impost, conversely, due to the absence of hoop forces in all the methods, the radial stresses are very similar.

Since, with MTLM, it is possible to choose the hoop forces' distribution, this method allows the highest control on the thrust line shape, and, consequently, returns the highest GSF value. On the contrary, since the thrust path obtained through TLA is controlled by only two parameters, it is less flexible and, therefore, a lower GSF value is obtained.

MEA, in general, is the most complete method for the evaluation of the stability of domes, but, for this kind of application, the results are inappropriate, since it cannot access the double curvature thrust surfaces that can be accessed using simpler methods, such as the MTLM.

\section{Conclusions}

In the present work, three Heyman-based methods are presented to assess the equilibrium of unreinforced masonry domes: the Thrust Line Analysis, the Modified Thrust Line Method, and the Membrane Equilibrium Analysis. TLA accounts only for stresses in the radial direction, while MTLM and MEA combine the radial response with circumferential stresses, and are able to model biaxial stress states. 
These methods were applied to the large hemispherical masonry dome of San Francesco di Paola. The effectiveness of these three approaches was compared in terms of the corresponding stress distributions and measured using the Geometric Safety Factor.

The geometrical safety factor obtained with TLA is 2.65 , corresponding to a maximum thickness reduction of $62.4 \%$. On the other hand, MTLM provides a GSF equal to 5.00, i.e., doubling the TLA value. In this case, the possible thickness reduction is about $80 \%$. The reason for this significant increase in the GSF with respect to TLA is that MTLM takes the hoop forces arising in the dome into account, and, as shown in Section 3, is more flexible with respect to TLA in terms of possible thrust surfaces.

Although the Membrane Equilibrium Analysis is the most sophisticated approach, it returns a GSF equal to 3.03. The GSF obtained with MEA is not so high with respect to one obtained with MTLM, because the version of MEA adopted in this work is limited to concave membrane shapes. The adoption of MEA remains valuable and necessary for geometries that cannot be studied using axial symmetry, such as, for the sake of example, cloister vaults or cross vaults, but results are excessive for the geometry under investigation in this work.

As is well known, TLA is a good starting point and a straightforward approach to assessing the stability of axis-symmetric masonry structures, giving conservative solutions. However, for the present case study, MTLM is the most effective approach, due to its simplicity and ability to explore a wide set of possible thrust surfaces. The drawback is that it cannot be applied to other vaulted structures or to different loading conditions, for which the adoption of more sophisticated tools, such as MEA, is needed.

Author Contributions: Conceptualization, C.C. (Concetta Cusano); A.M.; C.O. and V.P.; methodology, A.M.; C.O. and V.P.; software, A.M. and V.P.; validation, A.M. and V.P.; formal analysis, C.C. (Concetta Cusano); A.M.; C.O. and V.P.; data curation, C.C. (Concetta Cusano); writing-original draft preparation, C.C. (Concetta Cusano); A.M.; C.O. and V.P.; writing-review and editing, C.C. (Concetta Cusano); supervision, C.C. (Claudia Cennamo); funding acquisition, C.C. (Claudia Cennamo). All authors have read and agreed to the published version of the manuscript.

Funding: This research has been partially supported by the "AIM: Attraction and International Mobility", PON R\&I 2014-2020 Campania, n. 1849854-3 "Smart Secure and Inclusive Communities". CUP: E66C19000230005.

Conflicts of Interest: The authors declare no conflict of interest.

\section{References}

1. Heyman, J. The stone skeleton. Int. J. Solids Struct. 1966, 2, 249-279. [CrossRef]

2. Cennamo, C.; Cusano, C.; Angelillo, M. The neoclassical dome of San Francesco di Paola in Naples. A study on form and stability. In Proceedings of the XXIII Conference of the Italian Association of Theoretical and Applied Mechanics, Salerno, Italy, 4-7 September 2017; Volume 4, pp. 1439-1448.

3. Cennamo, C.; Cusano, C.; Angelillo, M. A limit analysis approach for masonry domes: The basilica of San Francesco di Paola in Naples. Int. J. Mason. Res. Innov. 2019, 4, 227-242. [CrossRef]

4. Cennamo, C.; Cusano, C.; Angelillo, M. On the statics of large domes: A static and kinematic approach for San Francesco di Paola in Naples. In Proceedings of the British Masonry Society, Milan, Italy, 9-11 July 2018; pp. 504-517.

5. Cennamo, C.; Cusano, C.; Fortunato, A.; Angelillo, M. A study on form and seismic vulnerability of the dome of San Francesco di Paola in Naples. Ing. Sismica 2018, 35, 88-108.

6. Cusano, C.; Cennamo, C.; Angelillo, M. Stability analysis and seismic vulnerability of large masonry domes. Mason. Int. 2019, $32,55-62$.

7. Cusano, C.; Cennamo, C.; Angelillo, M. Seismic vulnerability of domes: A case study. J. Mech. Mater. Struct. 2019, 13, 679-689. [CrossRef]

8. Block, P.; Lachauer, L. Three-dimensional (3D) equilibrium analysis of gothic masonry vaults. Int. J. Archit. Herit. 2014, 8, 312-335. [CrossRef]

9. Eddy, H.T. Researches in Graphical Statics; D.Van Nostrand: New York, NY, USA, 1878.

10. Angelillo, M.; Fortunato, A. Equilibrium of masonry vaults. In Novel Approaches in Civil Engineering; Springer: Berlin/Heidelberg, Germany, 2004; pp. 105-111.

11. Cusano, C.; Angjeliu, G.; Montanino, A.; Zuccaro, G.; Cennamo, C. Considerations about the static response of masonry domes: A comparison between limit analysis and finite element method. Int. J. Mason. Res. Innov. 2021, in press. 
12. Shin, H.V.; Porst, C.F.; Vouga, E.; Ochsendorf, J.; Durand, F. Reconciling elastic and equilibrium methods for static analysis. ACM Trans. Graph. TOG 2016, 35, 1-16. [CrossRef]

13. Guerra, G. Statica e Tecnica Costruttiva delle Cupole Antiche e Moderne; Istituto di Architettura Tecnica: Napoli, Italy, 1958.

14. Paris, V.; Pizzigoni, A.; Adriaenssens, S. Statics of self-balancing masonry domes constructed with a cross-herringbone spiraling pattern. Eng. Struct. 2020, 215, 110440. [CrossRef]

15. Dunn, W. The principles of dome construction: I and II. J. R. Inst. Br. Archit. 1908, 23, 401-412.

16. Cowan, H.J. Domes-Ancient and Modern. Archit. Sci. Rev. 1977, 20, 38-43. [CrossRef]

17. Schwedler, J.W. Die konstruktion der kuppeldächer. Z. Bauwes. 1866, 16, 7-34.

18. Huerta Fernández, S. Arcos, Bóvedas y Cúpulas. Geometría y Equilibrio en el Cálculo Tradicional de Estructuras de FábricaArcos, Bóvedas y Cúpulas: Geometría y Equilibrio en el Cálculo Tradicional de Estructuras de Fábrica; Instituto Juan de Herrera: Madrid, Spain, 2004.

19. Poleni, G. Memorie Istoriche Della Gran Copola Del Tempio Vaticano, E De'Danni Di Essa, E De'Ristoramenti Loro, Divise In Libri Cinqve; Padua Nella Stamperia del Seminario: Padua, Italy, 1748.

20. Como, M. Statica delle Costruzioni Storiche in Muratura: Archi, Volte, Cupole, Architetture Monumentali, Edifici Sotto Carichi Verticali e Sotto Sisma; Aracne Edizioni: Rome, Italy, 2015.

21. Rankine, W.J.M. Manual of Applied Mechanics; Griffin: London, UK, 1876.

22. Wolfe, W.S. Graphical Analysis: A Text Book on Graphic Statics; McGraw-Hill Book Company, Incorporated: New York, NY, USA, 1921.

23. Lau, W.W. Equilibrium Analysis of Masonry Domes. Ph.D. Thesis, Massachusetts Institute of Technology, Cambridge, MA, USA, 2006.

24. Ochsendorf, J.A. Collapse of Masonry Structures. Ph.D. Thesis, University of Cambridge, Cambridge, UK, 2002.

25. Block, P.P.C.V. Thrust Network Analysis: Exploring Three-Dimensional Equilibrium. Ph.D. Thesis, Massachusetts Institute of Technology, Cambridge, MA, USA, 2009.

26. Huerta Fernández, S. Mechanics of masonry vaults: The equilibrium approach. In Historical Constructions: Possibilities of Numerical and Experimental Techniques; Universidade do Minho: Guimaraes, Portugal, 2001.

27. Ochsendorf, J.A.; Block, P. Designing unreinforced masonry. In Form and Forces: Designing Efficient, Expressive Structures; Wiley: Hoboken, NJ, USA, 2010; pp. 215-245.

28. Como, M. Statics of Historic Masonry Constructions; Springer: Berlin/Heidelberg, Germany, 2013 ; Volume 1.

29. Manzanares, G.L.; Fernández, S.H. Estabilidad y Construcción de Cúpulas de Fábrica: El Nacimiento de la Teoría y su Relación con la Práctica. Ph.D. Thesis, Universidad Politécnica de Madrid, Madrid, Spain, 1999.

30. Huerta Fernández, S. Mecánica de las Bóvedas de la Catedral de Gerona; Universidad Politecnica de Madrid: Madrid, Spain, 2004.

31. Huerta, S.; Fuentes, P. The Cathedral of Girona and the Language of Equilibrium. In Konstruktionssprachen; Birkhäuser: Basel, Switzerland, 2020; pp. 101-130.

32. Huerta Fernández, S. Informe Sobre la Estabilidad de la Bóveda de la Antigua Cocina del Castillo de Bellver (Palma de Mallorca); E.T.S. Arquitectura (UPM): Madrid, Spain, 2008.

33. Cipriani, B.; Lau, W.W. Construction Techniques in Medieval Cairo: The Domes of Mamluk Mausolea (1250 AD-1517A. D.). In Proceedings of the Second International Congress on Construction History, Cambridge, UK, 29 March-2 April 2006; pp. 695-716.

34. Gesualdo, A.; Brandonisio, G.; De Luca, A.; Iannuzzo, A.; Montanino, A.; Olivieri, C. Limit analysis of cloister vaults: The case study of Palazzo Caracciolo di Avellino. J. Mech. Mater. Struct. 2019, 14, 739-750. [CrossRef]

35. Contestabile, M.; Babilio, E.; Fortunato, A.; Guerriero, L.; Lippiello, M.; Pasquino, M.; Angelillo, M. Static analysis of cross vaults: The case of the Cathedral of Casertavecchia. Open Constr. Build. Technol. J. 2016, 10, 329-345. [CrossRef]

36. Angelillo, M. Static analysis of a Guastavino helical stair as a layered masonry shell. Compos. Struct. 2015, 119, 298-304. [CrossRef]

37. Zessin, J.; Lau, W.; Ochsendorf, J. Equilibrium of cracked masonry domes. Proc. Inst. Civ. Eng. Eng. Comput. Mech. 2010, 163, 135-145. [CrossRef]

38. Davidson, S. Grasshopper Algorithmic Modeling for Rhino. Addons for Grasshopper. Available online: https://www. grasshopper3d.com/ (accessed on 17 March 2021).

39. McNeel. Rhino 6 per Windows. Available online: https://www.rhino3d.com/it/ (accessed on 17 March 2021).

40. Angelillo, M.; Babilio, E.; Fortunato, A. Singular stress fields for masonry-like vaults. Contin. Mech. Thermodyn. 2013, 25, 423-441. [CrossRef]

41. De Chiara, E.; Cennamo, C.; Gesualdo, A.; Montanino, A.; Olivieri, C.; Fortunato, A. Automatic generation of statically admissible stress fields in masonry vaults. J. Mech. Mater. Struct. 2019, 14, 719-737. [CrossRef]

42. Fortunato, A.; Babilio, E.; Lippiello, M.; Gesualdo, A.; Angelillo, M. Limit analysis for unilateral masonry-like structures. Open Constr. Build. Technol. J. 2016, 10, 346-362. [CrossRef]

43. Angelillo, M.; Montanino, A.; Pandolfi, A. On the Connection Between Geometry and Statically Determined Membrane Stresses in the Human Cornea. J. Biomech. Eng. 2020, 142, 051006. [CrossRef]

44. Olivieri, C.; Angelillo, M.; Gesualdo, A.; Iannuzzo, A.; Fortunato, A. Parametric design of purely compressed shells. Mech. Mater. 2021, 155, 103782. [CrossRef]

45. Fraternali, F.; Angelillo, M.; Fortunato, A. A lumped stress method for plane elastic problems and the discrete-continuum approximation. Int. J. Solids Struct. 2002, 39, 6211-6240. [CrossRef]

46. Iannuzzo, A.; Olivieri, C.; Fortunato, A. Displacement capacity of masonry structures under horizontal actions via PRD method. J. Mech. Mater. Struct. 2019, 14, 703-718. [CrossRef] 
47. Iannuzzo, A.; Van Mele, T.; Block, P. Piecewise rigid displacement (PRD) method: A limit analysis-based approach to detect mechanisms and internal forces through two dual energy criteria. Mech. Res. Commun. 2020, 107, 103557. [CrossRef]

48. Iannuzzo, A.; Dell'Endice, A.; Van Mele, T.; Block, P. Numerical limit analysis-based modelling of masonry structures subjected to large displacements. Comput. Struct. 2021, 242, 106372. [CrossRef]

49. Heyman, J. The Stone Skeleton: Structural Engineering of Masonry Architecture; Cambridge University Press: Cambridge, UK, 1997. 